\title{
Research on Magnetron Sputtering CNx Films Process Based on Orthogonal Experimental Design
}

\author{
Kang Peng ${ }^{1, a}$, Xin-min Shen ${ }^{1, b}$, Jian-zhao Zhou ${ }^{1, c}$ and Hong-fei Shang ${ }^{2, d}$ \\ ${ }^{1}$ College of Field Engineering, PLA University of Science and Technology, Nanjing 210007, China \\ ${ }^{2}$ State Key Laboratory of Tribology, Tsinghua University, Beijing 100084, China \\ apengk1005@163.com, bshenxmjfjlgdx2014@163.com, cpkandvs@sina.cn, dshanghf1234@sina.cn
}

Keywords: CNx films, orthogonal experimental design, surface roughness, magnetron sputtering.

\begin{abstract}
The test scheme of the magnetron sputtering CNx films was designed with the method of orthogonal experiment. The white-light interferometer was used to measure the surface morphology of CNx films. The effects of target current, duty ratio, nitrogen pressure, and bias voltage on surface roughness were investigated simultaneously. The weight orders of the influence of the above factors on the surface roughness of the film were obtained by means of range analysis and levels change trend chart. The results indicate that nitrogen pressure has the most significant effect on the surface roughness. According to the analysis, the optimum process parameters of $\mathrm{CNx}$ film prepared by magnetron sputtering were obtained, and the surface roughness of the $\mathrm{CNx}$ film prepared by the parameters was measured. The experimental results show that the film with the process parameters according to orthogonal test analysis has smaller surface roughness.
\end{abstract}

\section{Introduction}

CNx films have a good application prospect in industrial production and biomedicine for its excellent properties [1, 2], such as the high hardness, low friction coefficient, good biocompatibility, wear resistance, and so on. Many studies have shown that the process parameters and the preparation technology have a great influence on thin film structure and friction performance. Yang Fang-er and her team had done a lot of research to study the effects of deposition pressure, deposition bias, target distance and other parameters on the film structure [3]. However, their research is only limited to the single influencing factor, which lacks analysis of the parameters of the common changes under the comprehensive influences on their performances [4, 5]. Different process parameter on the film performance plays an important role. Therefore, attach great importance to the study of technological parameters, is of great significance for CNx film production applications.

The friction and wear property is one of the most important features of CNx films, and the level of the surface roughness has a significant effect on the friction and wear performance. The influence of various parameters on surface roughness of the film should be ordered, because it can effectively improve the friction and wear properties of thin films through preparation process. In this paper, the magnetron sputtering CNx films is used as the research object. The target current, duty ratio, nitrogen pressure, and bias voltage were selected as parameters. The effects weights order of different factors on the surface roughness were studied by orthogonal design.

\section{Experimental}

\subsection{Preparation of CNx films}

The CNx films were grown on $\mathrm{Si}(100)$ substrates with DC magnetron sputtering, as schematically shown in Fig. 1. The uniformity of deposition film was ensured by controlling the sample stage rotate at a constant speed. In this experiment, only one of two graphite targets was used considering to the size and quantity of samples, so that the film uniformity and coating efficiency can be guaranteed. 
The size of silicon wafer was $12 \mathrm{~mm} \times 12 \mathrm{~mm}$ and the thickness was $0.5 \mathrm{~mm}$. Firstly, the silicon wafers were ultrasonic cleaned with acetone and ethanol for $20 \mathrm{~min}$, respectively. Thereafter, the vacuum chamber was cleaned to remove the impurities in it. A base pressure of less than $5.0 \times 10^{-4} \mathrm{~Pa}$ was achieved in the chamber using a turbo-molecular pumping system. The silicon wafers were cleaned in vacuum chamber at a pressure of $2 \mathrm{~Pa}$ argon and voltage $800 \mathrm{~V}$ for $10 \mathrm{~min}$ to remove the impurities on the surfaces. Finally, the CNx films were deposited under the deposition parameters. The sample should be kept in vacuum chamber over $3 \mathrm{~h}$ to cool down. The white-light interferometer was used to observe the surface morphology and calculate the surface roughness then.

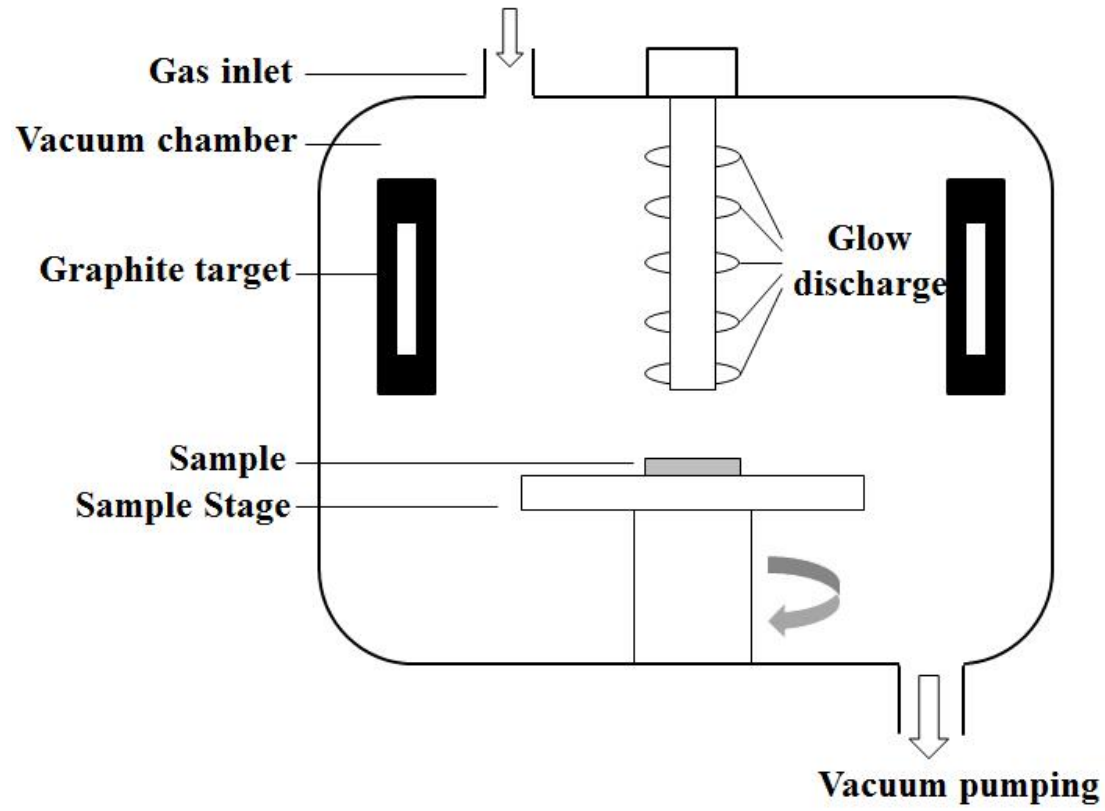

Fig. 1 Schematic diagram of the magnetron sputtering system

\subsection{Orthogonal design}

Target current, duty ratio, nitrogen pressure, and bias voltage (with A, B, C, D) were chose as the orthogonal test factors. A variety of forms were achieved through taking the corresponding value of these four factors. The orthogonal experiment factor level was shown in Table 1. Three levels were chose considering to the test time and materials.

Table 1 The orthogonal experiment factor level table

\begin{tabular}{|c|c|c|c|c|}
\hline \multirow{2}{*}{ Levels } & $\mathrm{A}$ & $\mathrm{B}$ & $\mathrm{C}$ & $\mathrm{D}$ \\
\cline { 2 - 5 } & Target current/A & Duty ratio & Nitrogen pressure/Pa & Bias voltage/V \\
\hline 1 & 0.5 & $20 \%$ & 0.4 & -100 \\
\hline 2 & 1.0 & $50 \%$ & 0.6 & -200 \\
\hline 3 & 1.5 & $80 \%$ & 0.8 & -300 \\
\hline
\end{tabular}

During testing, the collocation of various levels should be balanced to each factor in this experiment. Under the condition of without affecting the experimental results, test times should be reduced as much as possible [6, 7]. A orthogonal test table of $\mathrm{L}_{9}\left(3^{4}\right)$ was chose to finished this experiment, the design schemes and test results were shown in Table 2. In the orthogonal table, each column of different number had same occurrence, a scheme of nine tests was arranged according to the collocation of factors and levels. The surface roughness of CNx films was achieved with 9 kinds of process parameters and they were obtained with white-light interferometer. 
Table 2 The orthogonal design schemes and test results

\begin{tabular}{|c|c|c|c|c|c|}
\hline \multirow{3}{*}{ Number } & 1 & 2 & 3 & 4 & \multirow{2}{*}{ Surface roughness(Sa)/nm } \\
\cline { 2 - 5 } & A & B & C & D & 5.73 \\
\hline 1 & 1 & 1 & 1 & 1 & 8.97 \\
\hline 2 & 1 & 2 & 2 & 2 & 21.90 \\
\hline 3 & 1 & 3 & 3 & 3 & 5.61 \\
\hline 4 & 2 & 1 & 2 & 3 & 44.60 \\
\hline 5 & 2 & 2 & 3 & 1 & 5.08 \\
\hline 6 & 2 & 3 & 1 & 2 & 10.90 \\
\hline 7 & 3 & 1 & 3 & 2 & 3.32 \\
\hline 8 & 3 & 2 & 1 & 3 & 6.80 \\
\hline 9 & 3 & 3 & 2 & 1 & \\
\hline
\end{tabular}

\section{Results and discussion}

\subsection{Surface morphology}

The surface morphologies of CNx films observed by white-light interferometer were clearly shown in Fig. 2. It can be found that the surfaces of all films are smooth with only a little granular impurities. The values of surface roughness Sa are shown in Table 2. According to the results, the surface roughness value ranges obviously and it shows that the influence of different process parameters on the film surface structure is significant. 


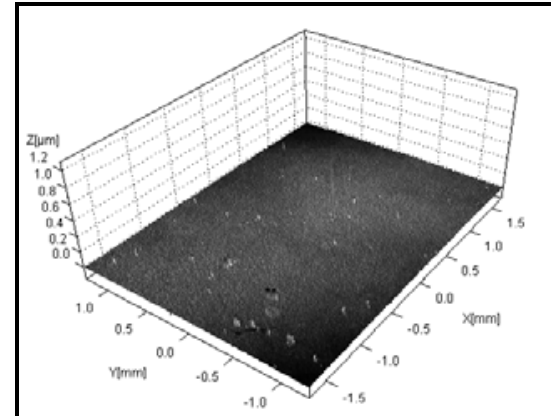

(a)

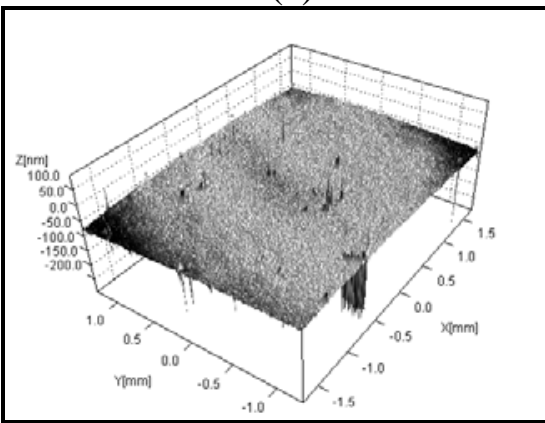

(d)

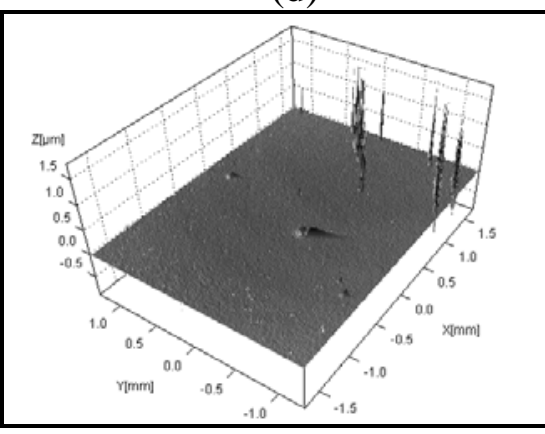

(g)

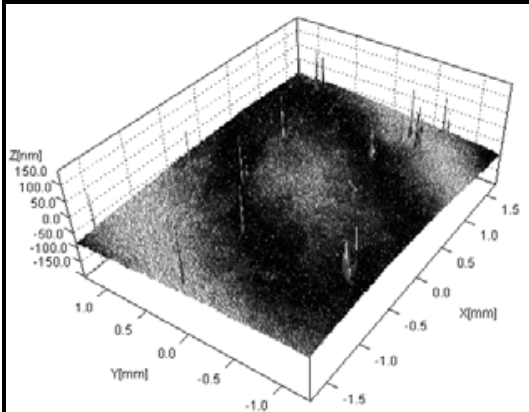

(b)

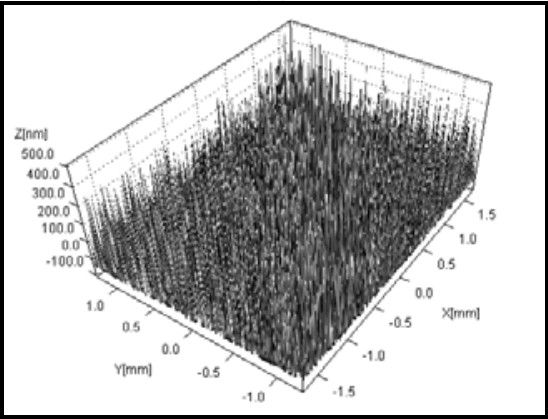

(e)

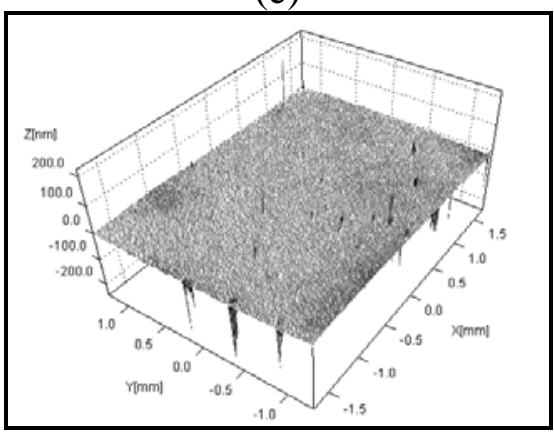

(h)

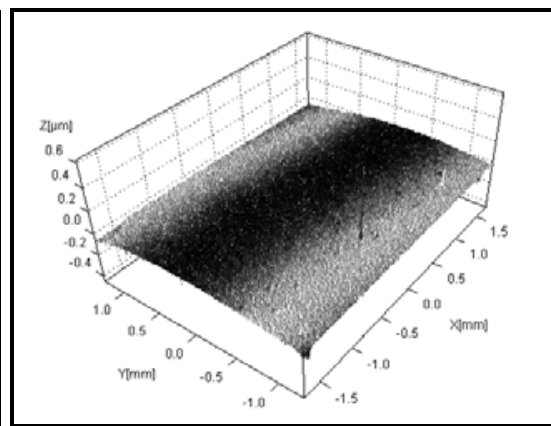

(c)

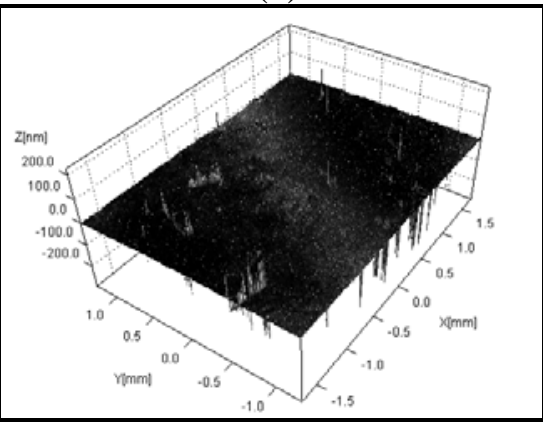

(f)

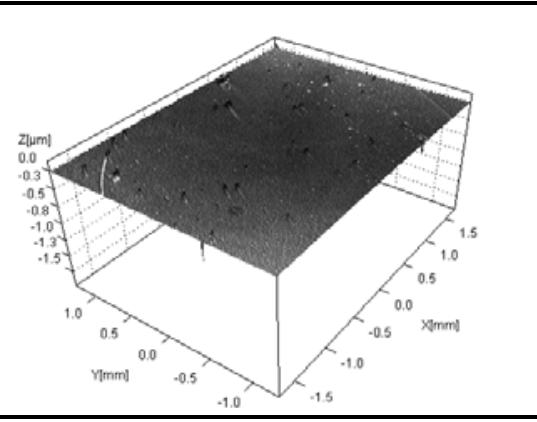

(i)

Fig. 2 Surface morphology obtained by white-light interferometer 


\subsection{Range analysis}

The method of range analysis was used to analyze the surface roughness of CNx films, as shown in Table 3. The $K_{1}, K_{2}$ and $K_{3}$ in the table represent the sum of surface roughness values of each factor in same level respectively. The $k_{1}, k_{2}, k_{3}$ are the average of surface roughness of these three levels, and $R$ is for the range. It was found that $R_{c}>R_{b}>R_{a}>R_{d}$ on the basis of the results. It means that the influence of nitrogen pressure on the film surface roughness is the largest among the four factors, and the ranges of other three factors have no obvious difference. It indicates these three factors have little influence on surface roughness. For thin film, the smaller the value of surface roughness, the friction performance is better, so the process parameters would be chose when the film deposited with it had lesser value of surface roughness. It was suggested that the best combination of process parameters is $A_{3} B_{1} C_{1} D_{2}$ with the target current $1.5 \mathrm{~A}$, duty ratio $20 \%$, nitrogen pressure $0.4 \mathrm{~Pa}$, bias voltage -200 $\mathrm{V}$.

Table 3 The range analysis table

\begin{tabular}{|c|c|c|c|c|}
\hline & 1 & 2 & 3 & 4 \\
\cline { 2 - 5 } & $\mathrm{A}$ & $\mathrm{B}$ & $\mathrm{C}$ & $\mathrm{D}$ \\
\hline$K_{1}$ & 36.60 & 22.24 & 14.13 & 57.13 \\
\hline$K_{2}$ & 55.29 & 56.89 & 21.38 & 24.95 \\
\hline$K_{3}$ & 21.02 & 33.78 & 77.40 & 30.83 \\
\hline$k_{1}$ & 12.20 & 7.41 & 4.71 & 19.04 \\
\hline$k_{2}$ & 18.43 & 18.96 & 7.13 & 8.32 \\
\hline$k_{3}$ & 7.01 & 11.26 & 25.80 & 10.28 \\
\hline$R$ & 11.42 & 11.55 & 21.09 & 10.72 \\
\hline
\end{tabular}

The best combination of process parameters $A_{3} B_{1} C_{1} D_{2}$ had not appeared in the orthogonal test. Therefore, another $\mathrm{CNx}$ film was deposited with the process parameters to verify the result by orthogonal test. Fig. 3 indicated the surface morphology of the film and it had a better surface roughness of $2.78 \mathrm{~nm}$. It can be concluded that the analysis based on orthogonal test is correct because of the better surface roughness according to the result of white-light interference. 


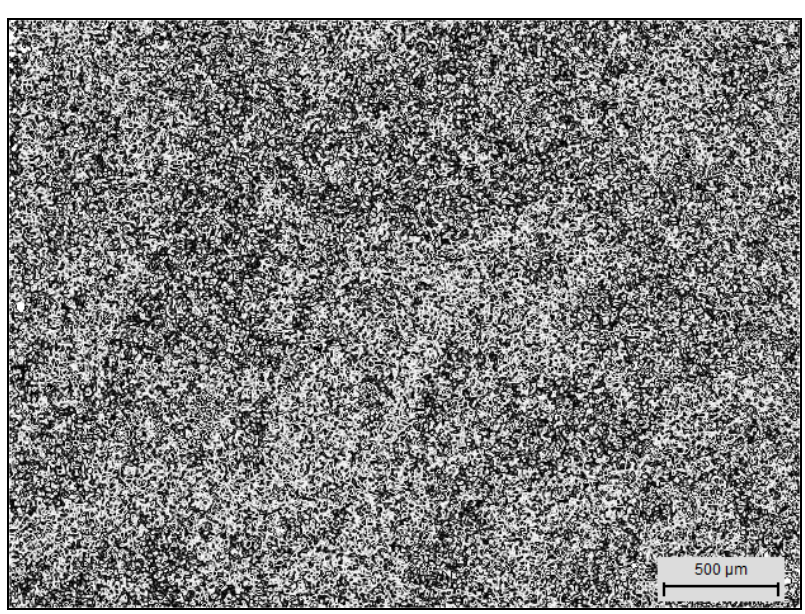

(a)

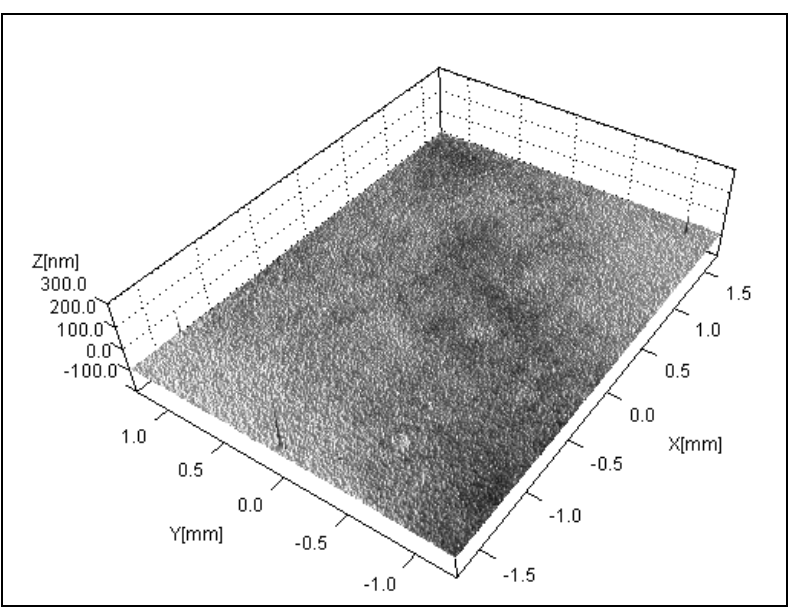

(b)

Fig. 3 Surface morphology $\left(A_{3} B_{1} C_{1} D_{2}\right)$

\subsection{Visual analysis}

The optimization solutions obtained through orthogonal experiment would not necessarily appear in the orthogonal experiment of combination usually. Factor levels change trend chart can be used to judge the influence of each factor besides range analysis [8]. According to average test results of various factors in the same level, using the level of the various factors affecting the film surface roughness as the abscissa and each level of the corresponding test results as the ordinate, the factor levels change trend chart was shown in Fig. 4. It showed that the better process parameters making the film surface roughness Sa the smallest is $A_{3} B_{1} C_{1} D_{2}$, the same as the result of range analysis.

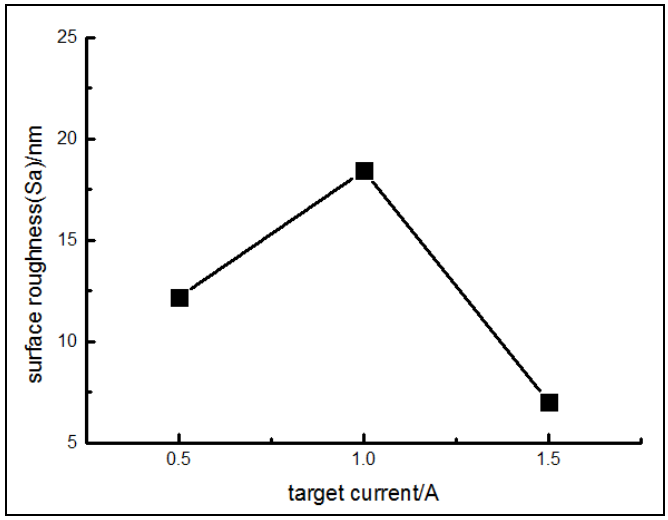

(a)

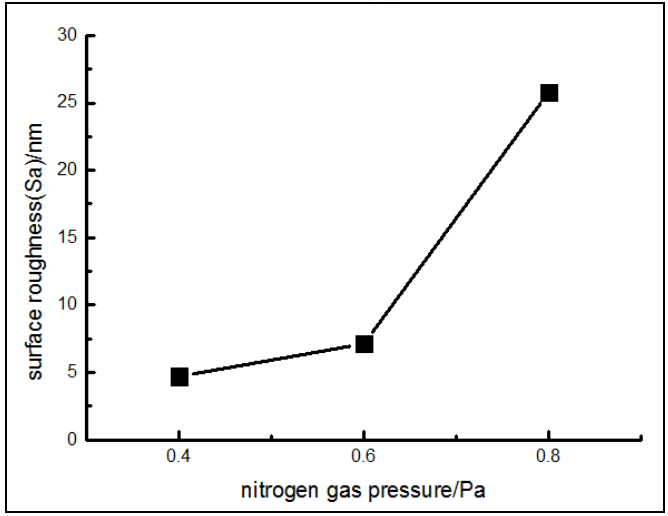

(c)

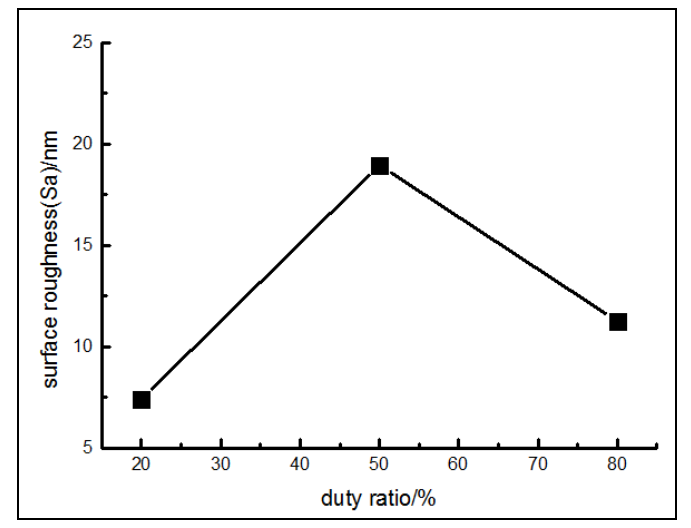

(b)

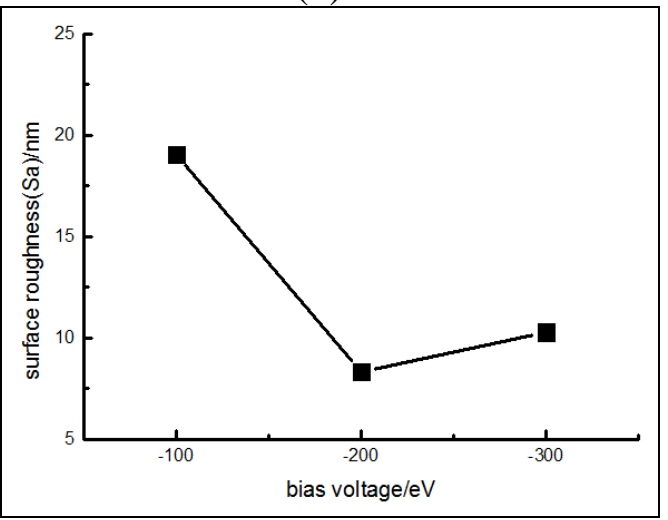

(d)

Fig. 4 Factor levels change trend chart 


\section{Conclusion}

(1) CNx films were deposited on $\mathrm{Si}(100)$ substrate using magnetron sputtering and white-light interferometer was used to observe the surface morphology of the films. The results show that the surface roughness Sa range from $3.32 \mathrm{~nm}$ to $44.6 \mathrm{~nm}$.

(2) Orthogonal experiment was arranged to analyze the process parameters. The results show that the parameters affect the film surface roughness in the following orders: nitrogen pressure, duty ratio, target current and bias voltage according to range analysis and visual analysis.

(3) Another CNx film was deposited with the optimal process parameters which were achieved through the analysis of orthogonal design. It is suggested that the analysis of orthogonal experiment is correct because the film has the smallest surface roughness of $2.78 \mathrm{~nm}$.

\section{Acknowledgments}

This work was supported by a grant from National Natural Science Foundation of China (Grant No. 51505498) and a grant from Natural Science Foundation of Jiangsu Province (No. BK20150714). Firstly, I would like to show my deepest gratitude to Dr. Shen Xin-min, who is also the corresponding author of this paper. I should also extend my gratitude to Prof. Zhou and Dr. Shang for their help on the experiment.

\section{References}

[1] P. F. Wang, M. Sugo, K. Adachi, Stable and super-low friction of amorphous carbon nitride coatings in nitrogen gas by using two-step ball-on-disk friction test, Lubrication Science. 27 (2015) 137-149.

[2] K. D. Bakoglidis, S. Schmidt, Low-temperature growth of low friction wear-resistant amorphous carbon nitride thin films by mid-frequency, high power impulse, and direct current magnetron sputtering, Journal of Vacuum Science and Technology. 33 (2015) 05E112.

[3] J. Q. Song, X. H. Zhen, F. E. Yang, et al, Effects of target to substrate distance on microstructure and tribological properties of pulsed laser deposited CNx films, China Surface Engineering. 01 (2013) 63-68.

[4] F. E. Yang, Z. L. Chen, X. H. Zhen, et al, Effects of deposition pressure on microstructure and tribological properties of pulsed laser deposited CNx films, Journal of Optoelectronics \& Laser. 06 (2013) 1126-1132.

[5] F. E. Yang, Z. L. Chen, X. H. Zhen, et al, Effects of deposition bias voltage on microstructure and mechanical properties of pulsed laser deposited CNx films, Journal of the Chinese Ceramic Society. 09 (2013) 1265-1270.

[6] J. Brocail, M. Watremez, L. Dubar, Identification of a friction model for modeling of orthogonal cutting, International Journal of Machine Tools \& Manufacture. 50 (2010) 807- 814.

[7] H. L. Chen, W.Y. Li, J. P. Jian, et al, Parametric design of spiral groove of mechanical seal with micro-pore and spiral groove face based on orthogonal design, Lubrication Engineering. 37 (2012) 21-24.

[8] M. Moha, M. R. Razfar, Numerical investigating the effect of machining parameters on residual stresses in orthogonal cutting, Simulation Modeling Practice and Theory. 18 (2010) 378 -389. 